\title{
An Alternative Approach to Case-Based Learning: The Use of Student-Authored Cases
}

\author{
Kai Wang \\ Nankai University, China \\ James Cappel \\ Central Michigan University \\ Zhenyu Huang \\ Central Michigan University \\ Hong Zhao \\ Nankai University, China
}

This study explores the use of student-authored cases in Case-Based Learning (CBL). While traditional $C B L$ leads to many important learning outcomes, additional benefits may be realized with the use of student-authored cases. This study compares the effects of using student-authored cases versus traditional $C B L$ in a computer programming course in China. The findings suggest that the student-authored case approach led to better understanding of course concepts, problem solving, and course performance compared to the traditional CBL approach. Thus, instructors might consider the use of student-authored cases a viable alternative to implementing case-based learning.

Keywords: Student-authored Cases, Case-based Learning, Active Learning

\section{INTRODUCTION}

Interest and motivation are among the most important factors that drive students to learn successfully (Razzouk \& Johnson, 2013). Case-based learning (CBL) has been shown as an effective method to enhance students' learning interest and motivation. For example, CBL is frequently used in the flipped classroom approach where it has helped to achieve effective learning outcomes (Yadav, Bozic, Gretter, \& Nauman, 2015; Yadav, Vinh, Shaver, Meckl, \& Firebaugh, 2014) .

However, it is a challenge for educators and instructional designers to design cases that lead to effective learning outcomes and high student satisfaction (Kim et al., 2006; Thiel et al., 2013). Among the challenges of CBL is that cases may be perceived by students as too easy or too difficult (Kim et al., 2006; Thiel et al., 2013). Overly simplified cases are not sufficiently engaging to students to adequately support learning goals (Thiel et al., 2013), while overly complex cases can cause obfuscation and 
frustration to students (Kim et al., 2006; Kulak \& Newton, 2014). With instructor-provided cases in a traditional CBL approach, students may also not have enough background to solve the case or may not be interested in its subject matter (Kim et al., 2006; Kulak \& Newton, 2014; Thiel et al., 2013). Students' diverse background presents a dynamic factor that varies from class to class, which makes it difficult to adopt a set of fixed cases to satisfy students from semester to semester (Kim et al., 2006).

Bloom's Taxonomy, a classic educational framework, postulates six learning levels from lowest to highest: knowledge, comprehension, application, analysis, synthesis and evaluation (Bloom, Engelhart, Furst, Hill, \& Krathwohl, 1956). This taxonomy was later revised by Anderson, Krathwohl, and Bloom (2001) and Krathwohl (2002) to emphasize knowledge acquisition actions with verbs and cognitive processes as shown in Figure 1. Instructors can utilize this taxonomy in planning course objectives and strategies. Some research studies have applied it to CBL instructional design. Harman et al. (2015) examined students' learning outcomes with CBL use in nutrition courses and found that CBL enhanced higher cognitive learning and professional skills development. In a Business course, Nkhoma et al. (2017) considered knowledge application, higher-order thinking, practice evaluation knowledge, and knowledge improvement using survey data and structural equation modelling. The findings revealed that with CBL, knowledge application had a positive impact on higher-order thinking, higher-order thinking had positive effect on evaluation knowledge, and practice evaluation knowledge produced a positive effect on knowledge improvement.

\section{FIGURE 1 REVISED BLOOM'S TAXONOMY}

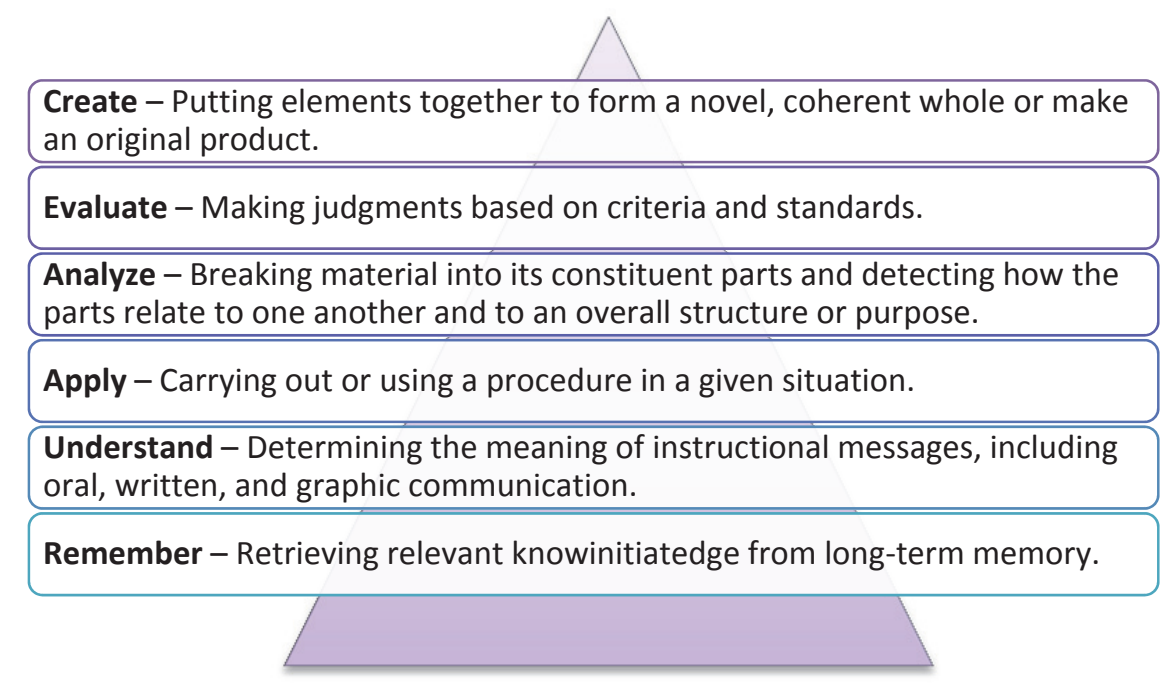

(Adapted from Krathwohl, 2002)

As indicated, the learning goals of the revised taxonomy are: Remember, Understand, Apply, Analyze, Evaluate, and Create. The highest level (Create) refers to assembling elements to form a novel, coherent whole, or to make an original product (Krathwohl, 2002). Addressing this top-level goal can also help realize the goals of the other levels as creating depends to some extent on these other levels. Thus, a Create learning goal is particularly important in instructional design. Yet, relatively few studies have considered this goal (Harman et al., 2015; Nkhoma, Lam, Richardson, Kam, \& Lau, 2016) due to the difficulty of implementation and the lack of engagement tools.

This study addresses the Create learning goal using student-authored cases. Whereas with a traditional CBL approach students are provided with a case by their instructor, the alternative CBL approach actively engages students by requiring them to create and solve their own cases. This approach was evaluated in this study in a computer programming course in China. The results provide insight about implementing this alternative approach to case-based learning. 


\section{LITERATURE REVIEW}

The benefits of case-based learning have been well-documented in disciplines such as engineering (Yadav et al., 2014), biochemistry (Shetty, Begum, Goud, \& Zaki, 2016), communication (Yoo \& Park, 2015), and computer programming (Tan, Guo, Zheng, \& Zhong, 2014). Research evidence indicates that CBL leads to positive learning outcomes and student satisfaction (Nkhoma et al., 2016; Raurell-Torreda et al., 2015; Yadav et al., 2014; Yoo \& Park, 2015). For example, Yadav et al. (2015) reported that cases were viewed by students as allowing them to see the real-world application of course concepts. Mahgoub and Nadeem (2012) found that students who used interactive CBL said it made complex concepts easier to understand. Raurell-Torreda et al. (2015) determined that CBL enables students to improve their communication and critical thinking skills. Jamkar, Yemul, and Singh (2006) observed that CBL helped students' clinical reasoning skills, self-learning skills, and their attitudes towards medical education.

Research studies have also found that CBL when coupled with other techniques such as cooperative learning (Rodriguez-Sanchez, Torrado-Carvajal, Vaquero, Borromeo, \& Hernandez-Tamames, 2016), competition (Lei et al., 2016), and group discussion (Cam \& Geban, 2011; Flynn \& Klein, 2001) can enhance the benefits of CBL. Rodriguez-Sanchez et al. (2016) utilized project-based learning plus peer review meetings to improve CBL. Lei et al. (2016) introduced competition into CBL in a clinical course, and found that it led to teaching efficiency, better student initiative, and improved final exam performance. Cam and Geban (2011) and Flynn and Klein (2001) used small group discussion with CBL, and determined that it improved students' attitudes and enhanced students' epistemological beliefs and motivation.

To date, only a limited number of studies have examined the use of student-authored cases in implementing case-based learning. Most of these studies have applied this approach in the accounting, medical, or education fields within Western cultures (e.g., Chu \& Libby, 2010; Hughes, 2017; Idowu, Muir, \& Easton, 2016). In contrast, the current study considers the use of student-authored cases in a computer programming course in a significantly different culture, China.

\section{METHODOLOGY}

This study was executed in a $\mathrm{C}++$ programming course taken by Math and Finance majors at a major university in China. Students self-selected their teams of 4 to 6 members. Some course sections consisted entirely of teams using the traditional CBL approach (instructor-provided cases) while teams in the other sections used the student-authored case (SAC) approach. The specific approach implemented in a given section was determined by the instructor. During the first week of the course, the instructor explained the team project for the semester and provided an overview of the upcoming content of the entire course.

In week 3, teams in the student-authored case sections were responsible for submitting a case proposal that identified a specific organization in a certain industry for their case, the systems scope and the main business problems their system would address. The instructor reviewed the proposals and provided feedback and suggestions to each team. If a certain case appeared overly simplistic or complex, for example, the instructor suggested that the team modify its case, so it was more likely to meet the requirements of the project. After the case proposal review, teams worked on their cases principally in an iterative fashion. That is, teams began creating programs and algorithms to solve specific types of business problems for their target organization. As individual solutions were created, more detailed information was added to the team case. Some teams discovered in the development phase that their initial case idea was not feasible to meet the project requirements, and they had to change their case idea. The teams ultimately submitted their final project in week 13 of the 16-week semester. This submission consisted of the case itself, its recommended solution that included executable code that was wellstructured, easy-to-read, and well documented, and a case video presentation. 


\section{Framework}

Figure 2 maps the learning activities of the alternative CBL approach (using student-authored cases) and the traditional CBL approach (using instructor-provided cases) to the six learning goals of the Revised Bloom's Taxonomy (Anderson et al., 2001; Krathwohl, 2002). As indicated, under both approaches, students engage in the learning activities shown in the bottom three boxes: classroom lecture, learning exercises completed inside and/or outside of class, and instructor-designed cases. These activities correspond to the bottom three educational goals of Remember, Understand, and Apply, respectively.

In addition, as indicated at the left of Figure 2, students in the alternative CBL approach participated in the learning activities in the top three boxes. Working in teams, students first analyzed and evaluated sample cases in a case library designed by students of previous semesters. This helped students to understand the case evaluation standards and to write better cases. Lastly, each team was required to create their own original, major-related case and its solution. The alternative CBL framework is the only one of the two approaches that addresses the highest educational level (Create) since it requires students to develop an original product (a case). The alternative CBL approach also supports the learning goals of Evaluate and Analyze since students review and evaluate cases written by previous students. Both the alternative and traditional CBL approaches also address the bottom five learning goals of Evaluate, Analyze, Apply, Understand, and Remember though the learning activities of: lecture-based study, learning exercises, and completing instructor-designed cases (Harman et al., 2015; Nkhoma et al., 2016; Nkhoma et al., 2017).

\section{Research Model}

The student-authored case approach requires students to engage in a higher level of "active learning" which has been defined as "a method of learning in which students are actively or experientially involved in the learning process" (Bonwell \& Eison, 1991). Many writers have noted the benefits of active learning, e.g., Melo, Hannois, Rodrigues, and Natal (2011), and reports such as "Engaged to Excel" by the U.S. President's Council of Advisors on Science and Technology cite research studies (Olson \& Riordan, 2012) that show active learning leads to benefits such as improved student performance and increased retention. For example, in a Physics course using active learning, students were found to have significantly higher test scores than those taught using more traditional methods (Gade \& Chari, 2013).

Compared to traditional lecture, which emphasizes passive listening, or the traditional CBL approach, where students solve instructor-provided cases, the alternative CBL strategy involves students creating and solving their own unique cases. Students must understand and reflect on course concepts to envision and describe situations (cases) for which a course-based solution can be applied.

Since the alternative CBL strategy is an active learning approach and other studies have found positive active learning outcomes, it is important to evaluate this potential outcome in this study.

In addition, a limited number of studies that involved students writing their own cases in other settings have reported positive results. For example, Chu and Libby (2010) found that students in a taxation course reported this approach enhanced their learning of technical information and encouraged them to make a link between related concepts. Hughes (2017) used student-authored cases in a graduate accounting course and found that students reported that they preferred this type of assignment, and that it exposed them to the complexities of course content. Based on the research results about active learning and student-authored cases, the first hypothesis proposed in this study is:

H1. Students in the alternative CBL condition will perform better than students in the traditional CBL condition in terms of understanding course concepts.

There is also evidence to suggest that students writing learning cases improves their problem solving ability (Brommer, Holzman, \& Rosc, 2007; Idowu et al., 2016). Compared to the traditional CBL approach where students normally provide only one solution to a problem, under the alternative CBL approach, students may be required to design multiple solutions to a problem. For example, the taxation study by Chu and Libby (2010) encouraged problem solving by requiring students to provide four 
plausible solutions to their case and to develop a full analysis of why their recommended solution was best. In a study by Brommer et al. (2007), education students who wrote cases reportedly learned course material more deeply, saw the broader implications of course content, and gained better problem-solving skills. Idowu et al. (2016) also found that medical students who wrote their own cases based on patient experiences were motivated to do additional research about their scenario and they improved their problem-solving process. Thus, we postulate that the alternative CBL method will improve students' problem-solving skills with the hypothesis:

H2. Students in the alternative $C B L$ condition will perform better than students in the traditional $C B L$ condition in terms of problem solving.

\section{FIGURE 2}

\section{RESEARCH FRAMEWORK}

\section{Alternative CBL} framework

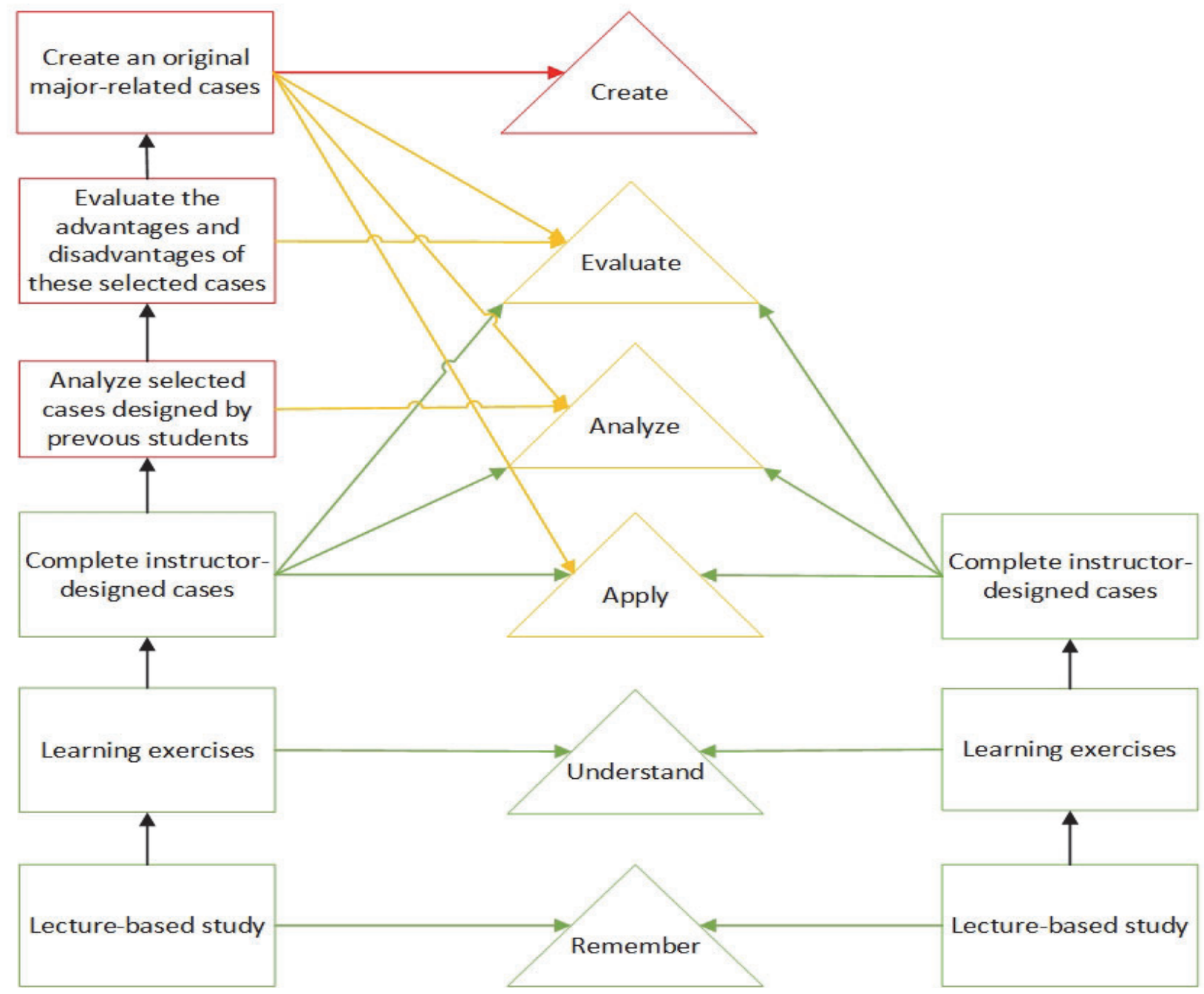

CBL allows students to see the practical application of course concepts and makes them more engaged, so this may lead to better course satisfaction (Du et al., 2013). This could especially be true for 
the alternative CBL approach, because students are designing a case related to their college major and are given a greater sense of ownership in the course. Thus, the third hypothesis of this study is:

H3. Students in the alternative CBL condition will will have higher course satisfaction than students in the traditional $C B L$ condition in terms of understanding course concepts.

In this study, the students also received a grade on their cases to motivate them to design higherquality cases. To develop an effective case, students need to understand course concepts thoroughly and how to solve the cases initially given to them by their instructor since these cases are loaded with appropriate programming concepts and challenging problems. Therefore, the following two hypotheses are also postulated:

H4. Students in the alternative CBL condition with higher case design scores will demonstrate a better understanding of course concepts than students in the traditional CBL condition.

H5. Students in the alternative CBL condition with higher case design scores will demonstrate better problem-solving performance than students in this condition with lower case design scores.

The five hypotheses of the study are summarized in Figure 3.

\section{FIGURE 3}

\section{ALTERNATIVE CBL APPROACH RESEARCH MODEL}

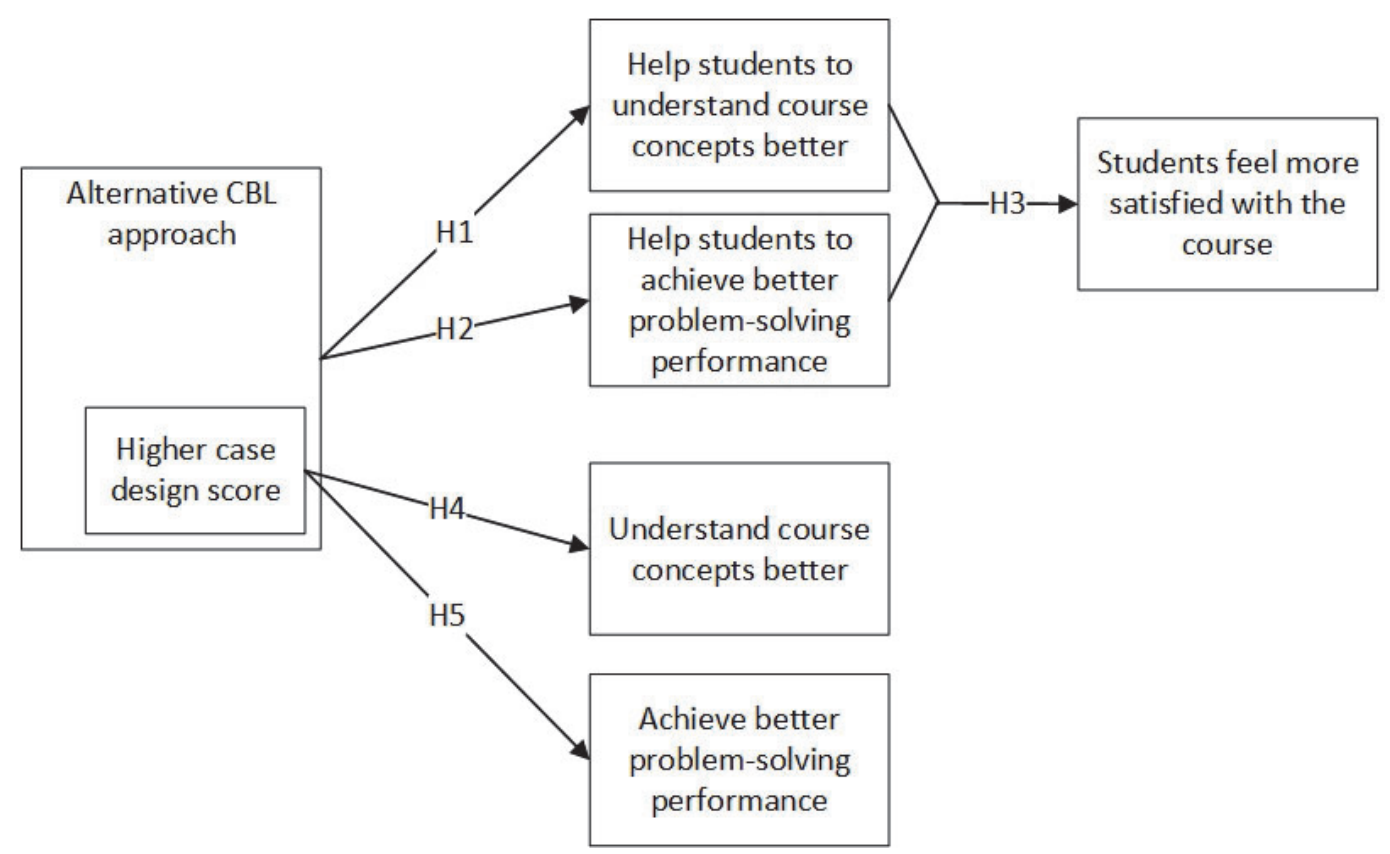

\section{Data}

This study involved a total of 362 students in the alternative CBL condition in seven course sections and 966 students in the traditional CBL condition in nineteen course sections. The authors used exam scores as an objective measure to evaluate students' knowledge acquisition and problem-solving performance, consistent with prior studies by Jamkar et al. (2006) and Raurell-Torreda et al. (2015). An anonymous survey was conducted to evaluate students' course satisfaction per Mahgoub and Nadeem (2012) toward the end of the course. The quality of each case designed by teams in the student-authored case condition was evaluated by the instructor using a rubric that addressed: the topic (relevance, novelty, 
and difficulty); case document (clarity of problem description and algorithm); sample solution (layout and structure of program code, proper declaration of variables, classes, and functions, comments, program excitability, and ability of code to solve the problem); and presentation video (clarity, recording/editing quality, and attire).

Exam scores and satisfaction ratings were collected from all subjects. Four types of exam questions were used: multiple-choice, true-false, program analysis, and program completion. The program analysis questions required students to analyse a given block of program code and determine the output the code would generate. The program completion questions involved filling in blanks to finish the missing elements of a block of code. The multiple-choice and true-false questions measured the understanding of course concepts. The program analysis and program completion questions assessed the students' problemsolving performance.

The case design scores earned by the teams were normalized to $[0,100]$ by formular (1), and then the scores were converted into five letter grades by formular (2) for subsequent statistical analysis.

Table 1 presents a categorization of students in the treatment classes by their team's case ratings.

NScore $=\frac{\text { Score }}{\text { Full Score }} * 100$

Grade $=\left\{\begin{array}{l}A, \text { if NScore } \geq 90 \\ B, \text { if NScore } \geq 80 \text { and NScore }<90 \\ C, \text { if NScore } \geq 70 \text { and NScore }<80 \\ D, \text { if NScore } \geq 60 \text { and NScore }<70 \\ E, \text { otherwise }\end{array}\right.$

$\operatorname{Group}_{\alpha}=A \cup B, \operatorname{Group}_{\beta}=C \cup D$

TABLE 1

CASE RATING DISTRIBUTION

\begin{tabular}{ccc}
\hline $\begin{array}{c}\text { Case } \\
\text { rating }\end{array}$ & $\begin{array}{c}\text { Number of } \\
\text { students }\end{array}$ & Percentage \\
\hline A & 84 & $23.2 \%$ \\
B & 129 & $35.6 \%$ \\
C & 84 & $23.2 \%$ \\
D & 50 & $13.8 \%$ \\
E & 15 & $4.2 \%$ \\
\hline \hline Total & 362 & $100.0 \%$ \\
\hline
\end{tabular}

\section{Statistical analysis}

Chi-square tests were applied to compare the differences between subjects in the two conditions for exam scores and course satisfaction. Total exam scores, the scores for each type of questions, and satisfaction ratings were analyzed using Chi-square tests.

\section{RESULTS}

As shown in Figure 4, students in the alternative CBL condition achieved significantly higher average exam scores than those in the traditional CBL condition, 66.87 compared to 63.06. The p-value for this difference was 0.003 based on the Chi-square test. However, the difference between students in the two conditions for the second measure, course satisfaction, was not significant, with a p-value of 0.617 . 


\section{FIGURE 4}

\section{EXAM SCORES AND COURSE SATISFACTION}

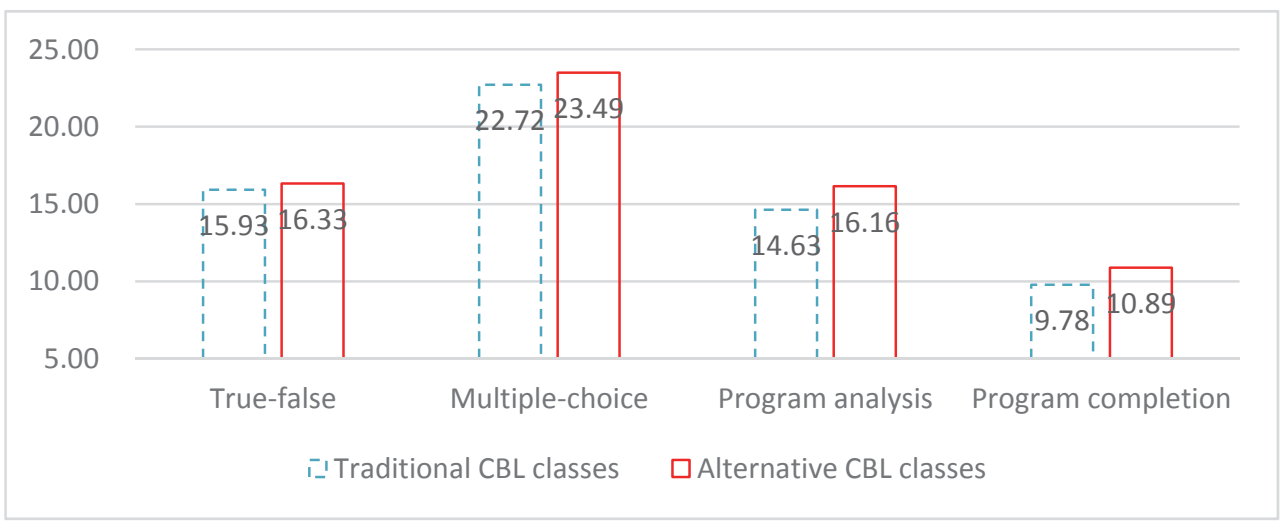

As indicated in Figure 5, students in the alternative CBL condition had a higher average score for all four question types than students in the traditional CBL condition. As noted, the true-false and multiplechoice questions were used to measure students' understanding of course concepts and the program analysis and program completion questions assessed students' problem-solving performance.

FIGURE 5

EXAM SCORES BY QUESTION TYPE

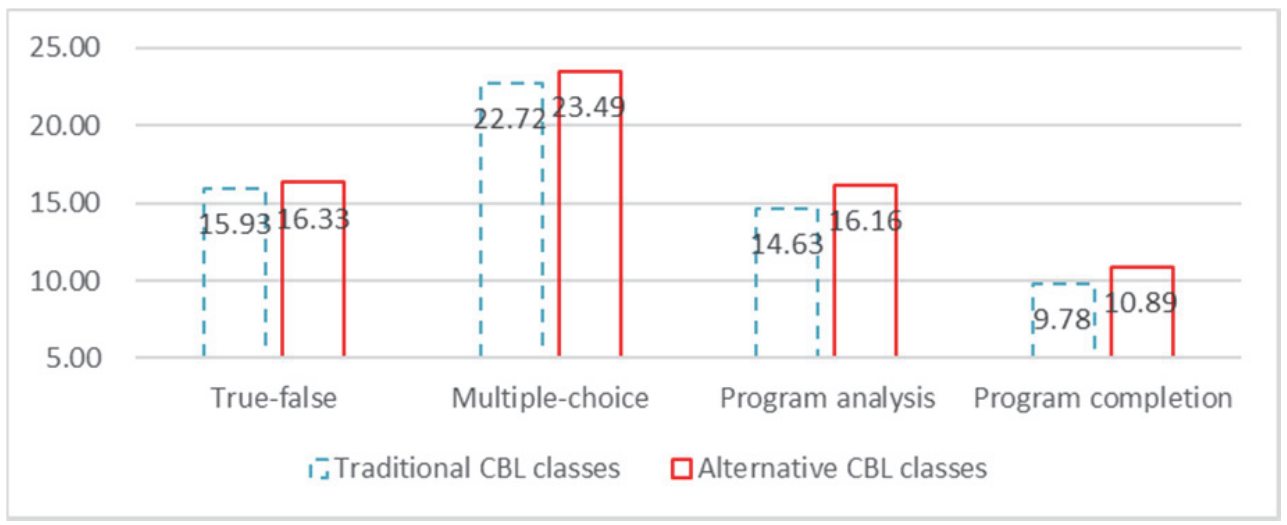

In this study, each question type had a different possible total score. The total scores for true-false, multiple-choice, program analysis, and program completion questions were 20, 30, 25, and 25, respectively. To make an equivalent comparison, data standardization was conducted to normalize the range of scores into $[0,100]$ for each question type. This comparison based on standardized scores by question type is shown in Figure 6. This analysis indicates that the student performance on true-false and mutiple-choice questions in all classes is noticeably higher than for the program analysis and program completion questions. 
FIGURE 6

STANDARDIZED EXAM SCORES BY QUESTION TYPE

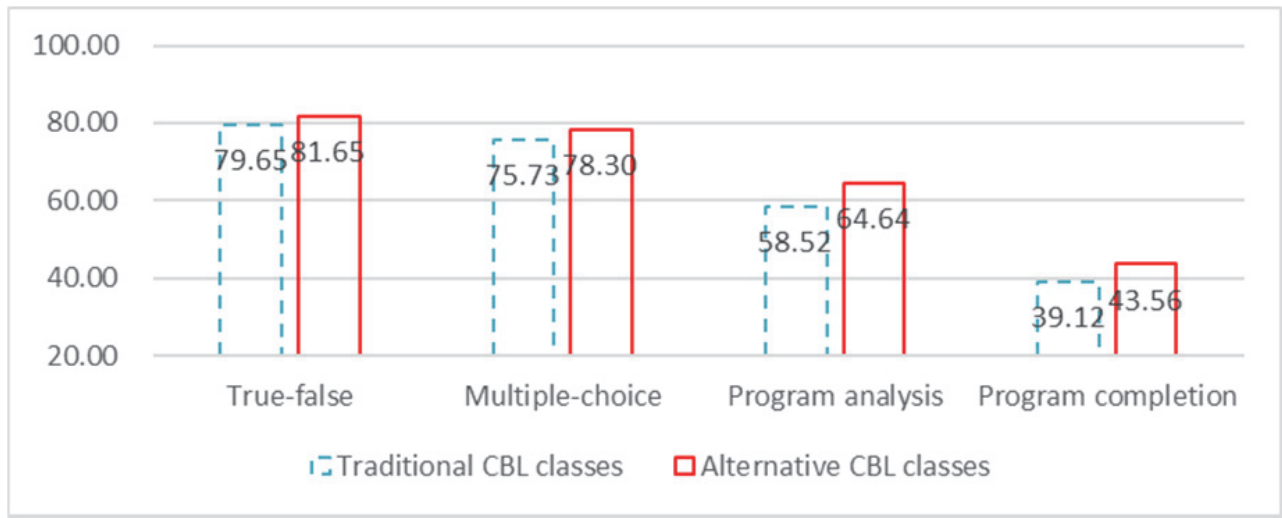

Finally, chi-square tests were applied to test for significant differences in the standardized exam scores by question type between students in the two conditions. As shown in TABLE 2, these measures were statistically significant for all four question types. This indicates that students in the studentauthored case sections performed significantly better on all four types of questions than students in the traditional CBL sections. We further analyzed students' scores in understanding course concepts (based on the true-false and multiple-choice questions) and problem solving (based on program analysis and program completion questions). The chi-square tests indicate significant differences with $\mathrm{p}$-values of 0.005 and 0.003 , respectively. Therefore, $\mathrm{H} 1$ and $\mathrm{H} 2$ are supported. Students in the alternative CBL condition performed better in understanding course content $(\mathrm{H} 1)$ and problem solving $(\mathrm{H} 2)$ than students in the traditional CBL condition.

Lastly, this study assessed the exam scores of students in the student-authored case condition based on a comparison of their case rating scores. The results are shown in Figure 7 and 8 . The findings indicate that students who achieved higher case rating scores performed better in terms of understanding course concepts and problem-solving than those with lower case scores. As shown in the figures, students with case rating $\mathrm{A}$ and $\mathrm{B}$ performed similarly in the exam, and those with case rating $\mathrm{C}$ and $\mathrm{D}$ performed similarly. Therefore, before conducting Chi-square test, we combined Group A and Group B into Group $_{\alpha}$, Group C and Group D into Group, , as is shown in (3). Since the number of students with the case rating E was very small (4\%), they were not included in the Chi-square test.

TABLE 2

CHI-SQUARE TESTS FOR EXAM SCORES BY CLASS TYPE

\begin{tabular}{lcccc}
\hline \multirow{2}{*}{ Variable/Question type } & Alternative & Traditional & \multicolumn{2}{c}{ Chi-square test } \\
& CBL classes & CBL classes & $\chi^{2}$ & $\mathrm{p}$-value \\
\hline Understanding course concepts & $\mathbf{3 9 . 8 2}$ & $\mathbf{3 8 . 6 5}$ & $\mathbf{1 4 . 6 4 7}$ & $\mathbf{0 . 0 0 5} * * *$ \\
True-false & 16.33 & 15.93 & 8.756 & $0.067^{*}$ \\
Multiple-choice & 23.49 & 22.72 & 13.863 & $0.008^{* * *}$ \\
Problem solving & $\mathbf{2 7 . 0 5}$ & $\mathbf{2 4 . 4 1}$ & $\mathbf{1 6 . 3 5 1}$ & $\mathbf{0 . 0 0 3} * * *$ \\
Program analysis & 16.16 & 14.63 & 11.610 & $0.021^{* *}$ \\
Program completion & 10.89 & 9.78 & 12.903 & $0.012^{* *}$ \\
\hline
\end{tabular}

* significant at $0.1 * *$ significant at $0.05 * * *$ significant at 0.01

The results of the chi-square tests are shown in TABLE 3. As indicated, all the tests were statistically significant between Group $\alpha$ and Group $\beta$ except for the true-false questions. The most significant differences occurred for the problem-solving measures, program analysis and program completion. The 
"understanding course content" scores were calculated by adding students' true-false and multiple choice question scores, and the "problem solving" scores were derived by adding the program analysis and program completion scores together. The chi-square tests show significant differences with $\mathrm{p}$-values of 0.028 and 0.003, respectively, between Group $_{\alpha}$ and $\operatorname{Group}_{\beta}$. Therefore, H4 and H5 are supported that students in the student-authored case sections who designed better cases $\left(\right.$ Group $\left._{\alpha}\right)$ performed better in terms of both understanding course content (H4) and problem solving (H5) than students who designed cases of lesser quality $\left(\operatorname{Group}_{\beta}\right)$.

FIGURE 7

\section{EXAM SCORES BY CASE RATING FOR STUDENTS IN THE ALTERNATIVE CBL CLASSES}

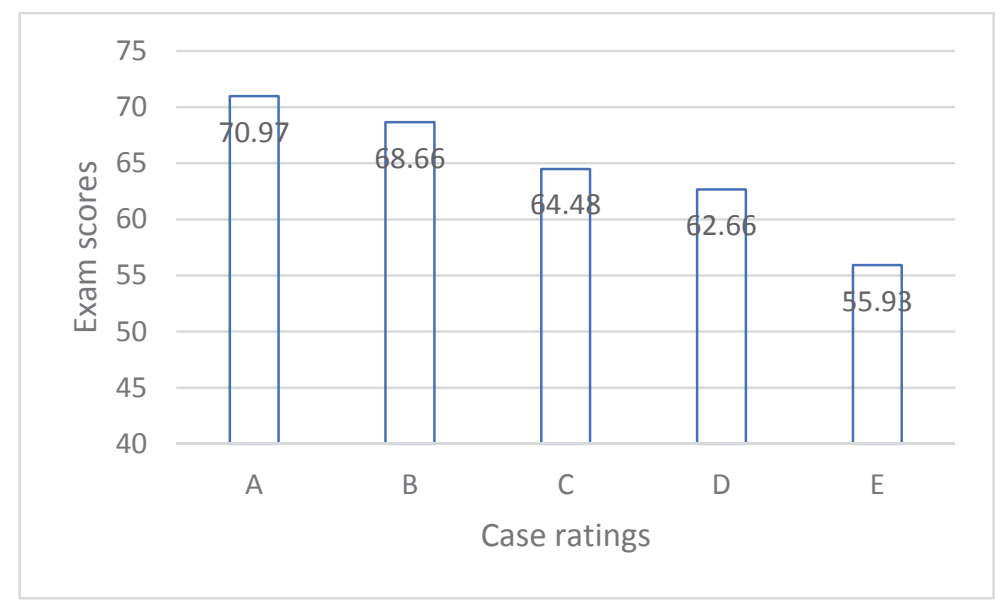

FIGURE 8

EXAM SCORES BY CASE RATINGS BY QUESTION TYPE FOR STUDENTS IN THE ALTERNATIVE CBL CLASSES

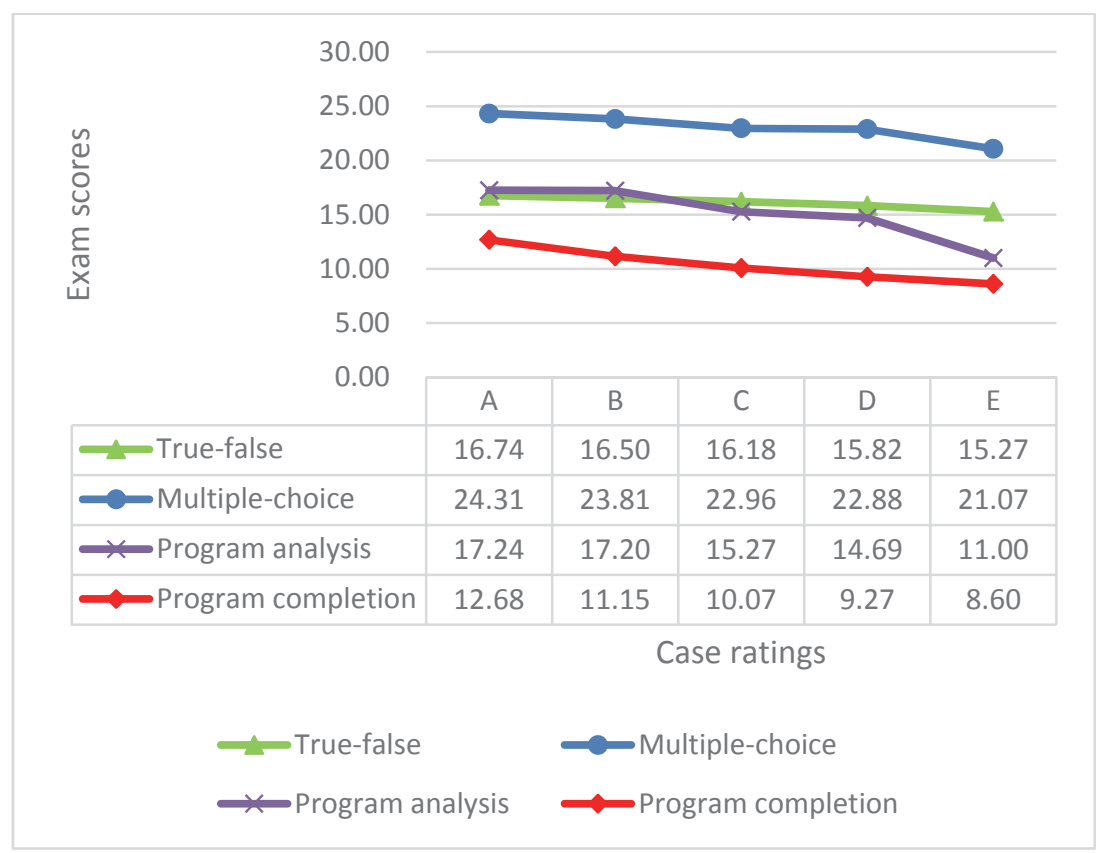


TABLE 3

CHI-SQUARE TESTS FOR EXAM GRADES BETWEEN Group ${ }_{\alpha}$ AND Group $_{\beta}$

\begin{tabular}{lcccc}
\hline \multicolumn{1}{c}{ Variable/Question type } & Group $_{\alpha}$ & Group $_{\beta}$ & \multicolumn{2}{c}{ Chi-square test } \\
& & & $\chi^{2}$ & p-value \\
\hline Understanding course concepts & $\mathbf{4 0 . 6 0}$ & $\mathbf{3 8 . 9 7}$ & $\mathbf{1 0 . 8 4 3}$ & $\mathbf{0 . 0 2 8 * *}$ \\
True-false & 16.59 & 16.04 & 7.186 & 0.126 \\
Multiple-choice & 24.01 & 22.93 & 8.643 & $0.070^{*}$ \\
Problem solving & $\mathbf{2 8 . 9 6}$ & $\mathbf{2 4 . 8 2}$ & $\mathbf{1 6 . 2 4 2}$ & $\mathbf{0 . 0 0 3 * * *}$ \\
Program analysis & 17.22 & 15.05 & 11.356 & $0.021^{* *}$ \\
Program completion & 11.75 & 9.77 & 9.044 & $0.059^{*}$ \\
\hline
\end{tabular}

* Significant at $0.1 * *$ significant at $0.05 * * *$ significant at 0.01

\section{CONCLUSION AND DISCUSSION}

This study provides important insight about the outcomes of using student-authored cases in implementing case-based learning. While CBL has been widely used, relatively few studies have investigated its effects using student-authored cases. Most SAC studies to date have examined its use in the accounting, medical, or education fields in Western countries. In addition, most prior SAC studies have involved case written by individuals (Brommer, Holzman, \& Rosc, 2007; Chu \& Libby, 2010; Hughes, 2017). In contrast, the current study examined the SAC approach using a team-based approach in a computer science course in China.

The results in terms of the research model are summarized in Figure 9, with an "** to indicate any statistically significant findings. As indicated, the findings demonstrate that the alternative CBL approach using student-authored cases resulted in better understanding of course concepts and problem solving than the traditional CBL approach. In addition, among the alternative CBL approach subjects, those students with higher case ratings performed better in terms of understanding course concepts and problem solving than students with lower case ratings. Thus, four of the five hypotheses of the study were supported. These findings are consistent with a limited number of studies in other fields that used student-authored cases that reported positive outcomes such as students thinking this approach enhanced their learning (Chu \& Libby, 2010; Hughes, 2017) and led to better problem solving (Brommer et al., 2007; Chu \& Libby, 2010; Idowu et al., 2016). The current study suggests that student-authored case approach can be successfully applied in another discipline (computer science) and in a significantly different culture (China). The results of the current study are also consistent with the active learning literature that requiring students to actively engage in a course through challenging activities leads to more effective learning outcomes (Bonwell \& Eison, 1991; Melo et al., 2011; Olson \& Riordan, 2012). The confluence of these findings makes sense intuitively since the alternative CBL approach is fundamentally an application of active learning.

The one hypothesis of this study that was not significant was that the alternative CBL approach leads to higher course satisfaction (H3). This result may be attributable to the manner in which this measure was assessed. A standard course evaluation form was administered to students near the end of the semester to measure course satisfaction. This instrument focused on the entire course, not the specific CBL approach used. Because many factors influence course satisfaction, the authors recommend that future researchers assess satisfaction on the use of the approach itself, not the entire course. 


\section{FIGURE 9}

\section{TESTED RESEARCH MODEL}

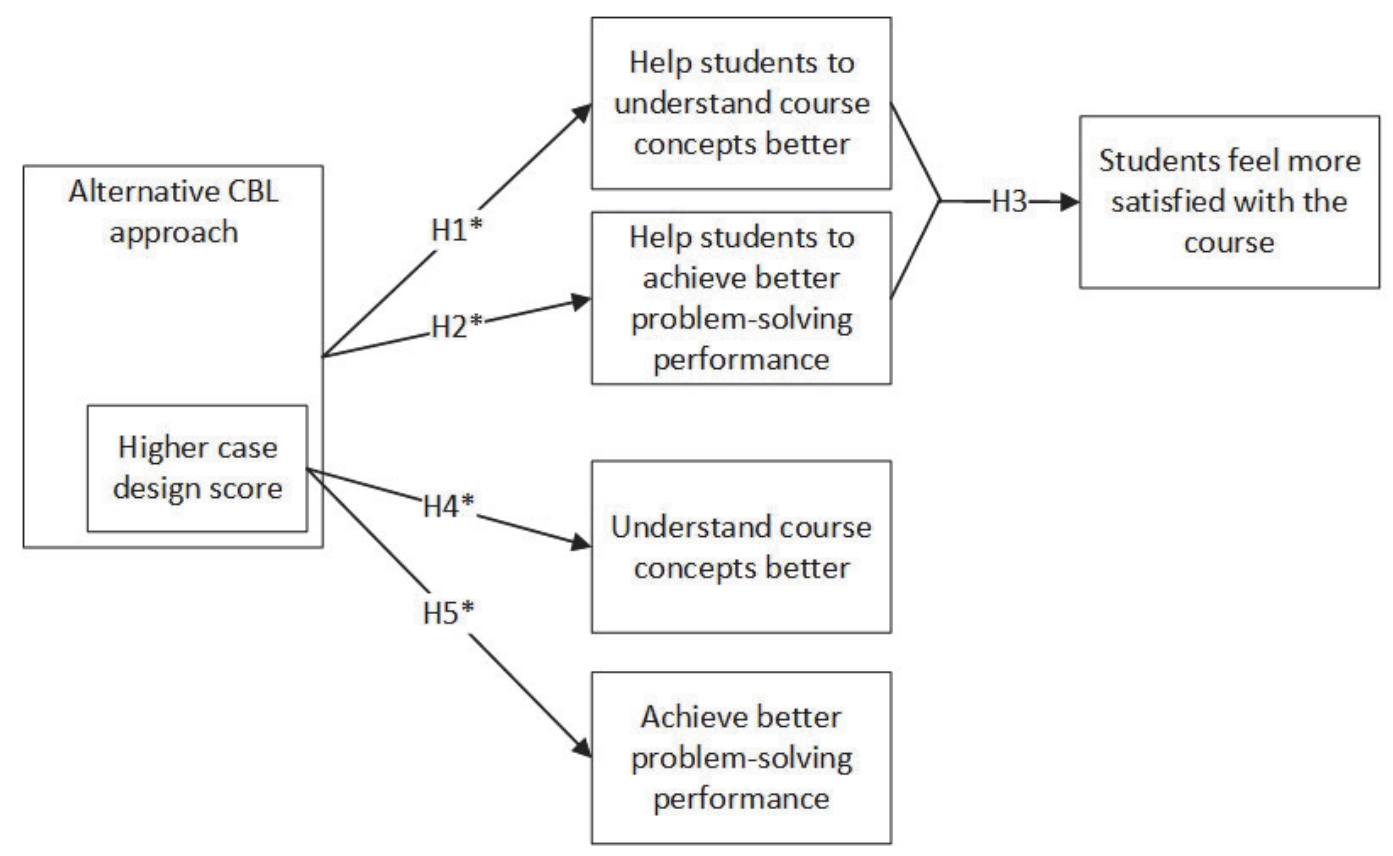

From a pedagogical perspective, the student-authored case approach to CBL appears to have a number of important benefits. First, the SAC approach may heighten students' interest and motivation since they are challenged to identify problems and develop solutions to issues related to their major field of study. This provides students with greater control over their learning and feelings of course ownership, compared to the traditional CBL approach where a case is provided by the instructor that students may or may not be interested in solving. With the SAC approach of using a major-related, self-selected topic, students will be able to understand the theme of a case more quickly and the problem-solving process should be more efficient. Thus, the student-authored case approach may lead to students being more engaged in the course project and the course overall.

Second, unlike the traditional CBL approach, the alternative CBL approach addresses the top learning goal (Create) in the Revised Bloom's Taxonomy. Student teams are given the opportunity to be innovative in creating a case of their own and its solution. As noted earlier, relatively few studies have addressed this top goal of Bloom's Revised Taxonomy. The study's results suggest that students in the alternative CBL condition who developed better cases as measured by case ratings, performed significantly better in program analysis and program completion than those who had lower case ratings. Thus, the creation of higher-quality cases appears to be associated with students engaging in a deeper level of thinking that ultimately leads to better learning outcomes.

Third, with the alternative CBL approach, a pool of quality cases can be built up over time to benefit students and instructors. Based on the authors' experience of using this approach, roughly the top 20\% of cases written in previous semesters are of appropriate quality to add to the case library. Having these examples of good cases available to current students sets better expectations about the project and motivates students to develop better cases. Using student-authored cases also can potentially save instructors time versus having to write their own cases or search for and adapt cases from other sources.

Lastly, having students write their own cases provides greater assurance that the cases used in a course are unique and challenging. In the age of the Internet, if standard, widely-available cases are used from other sources, some students may search and find solutions to these cases over the Internet. If this occurs, it is a serious impediment to students' problem solving and learning. Of course, with the SAC 
approach, instructors need to take reasonable steps to ensure that student-authored cases are not plaigarized from other sources.

Despite the benefits of the SAC aproach, it is not without its challenges. Based on the authors' experience of using this approach over multiple semesters, a few issues may arise. First, some student teams will likely struggle to come up with a case idea. To help overcome this problem, instructors should provide a clear description of the project, its expectations, and an overview to the course content for the semester very early in the course. They also need to make the case library available to students beginning in the first week and explain how to use this case library. To ensure that the student teams have sufficient time to develop a good, viable case idea, it is recommended that students be given at least to the end of the third week of a 16-week semester to submit their case proposals. It is important for the instructor to provide detailed, meaningful, timely feedback of these proposals to students. This will enable students to make modifications to their case idea as needed. Throughout the case development process, instructors should expect to spend a signficant amount of time mentoring students. Patience and dedication are required as students work through various case problems and iterations.

It should be noted that while this study involved numerous (more than 1,000) participants, it did not employ an experimental design. The assignment of teams to the two different CBL conditions was not random, but dependent upon instructors' willingness to adopt the alternative CBL approach. This ensured that instructors were not compelled to adopt an approach for which they did not feel comfortable. Thus, this study provides exploratory data to suggest the alternative CBL approach using student-authored cases can produce positive outcomes. As such, instructors can consider this aproach a viable option in implementing case-based learning. To assess the outcomes of student-authored cases more fully, there is a need for further research using experimental designs. This research could addresses the use of studentauthored cases in other disciplines, in different countries and cultures, and varying the unit of analysis (individual versus group). In addition, researchers could test the effects of the SAC approach using a different student-instructor interaction model, a different case evaluation rubric, or altering group size or other variables. The outcomes of this analysis could assist educators in determining how to apply studentauthored cases most effectively in different learning situations.

\section{REFERENCES}

Anderson, L. W., Krathwohl, D. R., \& Bloom, B. S. (2001). A Taxonomy for Learning, Teaching, and Assessing : A Revision of Bloom's Taxonomy of Educational Objectives. New York: Longman.

Bonwell, C., \& Eison, J. (1991). Active Learning: Creating Excitement in the Classroom. ASHE-ERIC Higher Education Report, 10(3), 25-29.

Brommer, C., Holzman, J., \& Rosc, J. D. (2007). Cases, writing, and students becoming teachers: A new way to enhance undergraduate science education. Faseb Journal, 21(5), A218-A218.

Cam, A., \& Geban, O. (2011). Effectiveness of Case-Based Learning Instruction on Epistemological Beliefs and Attitudes Toward Chemistry. Journal of Science Education and Technology, 20(1), 26-32.

Chu, L., \& Libby, T. (2010). Writing Mini-Cases: An Active Learning Assignment. Issues in Accounting Education, 25(2), 245-265.

Du, G. F., Li, C. Z., Shang, S. H., Xu, X. Y., Chen, H. Z., \& Zhou, G. (2013). Practising Case-based Learning in Oral Medicine for Dental Students in China. European Journal of Dental Education, 17(4), 225-228.

Flynn, A. E., \& Klein, J. D. (2001). The Influence of Discussion Groups in a Case-based Learning Environment. Etr\&D-Educational Technology Research and Development, 49(3), 71-86.

Gade, S., \& Chari, S. (2013). Case-based Learning in Endocrine Physiology: An Approach Toward SelfDirected Learning and the Development of Soft Skills in Medical Students. Advances in Physiology Education, 37(4), 356-360. 
Harman, T., \& Babatunde, O. T., et al. (2015). Case-based Learning Facilitates Critical Thinking in Undergraduate Nutrition Education: Students Describe the Big Picture. Journal of the Academy of Nutrition and Dietetics, 115(3), 378-388.

Hughes, S. B. (2017). Student-authored IFRS teaching cases based on European Securities and Markets Authority reports: Experiences from case writing and subsequent classroom use. Journal of Accounting Education, 41, 58-74.

Idowu, Y., Muir, E., \& Easton, G. (2016). Problem-based learning case writing by students based on early years clinical attachments: a focus group evaluation. JRSM Open, 7(3).

Jamkar, A., Yemul, V., \& Singh, G. (2006). Integrated Teaching Programme with Student-Centred Casebased Learning. Medical education, 40(5), 466-467.

Kim, S., Phillips, W. R., Pinsky, L., Brock, D., Phillips, K., \& Keary, J. (2006). A Conceptual Framework for Developing Teaching Cases: A Review and Synthesis of the Literature Across Disciplines. Medical education, 40(9), 867-876.

Krathwohl, D. R. (2002). A Revision of Bloom's Taxonomy: An Overview. Theory into Practice, 41(4), 212-218.

Kulak, V., \& Newton, G. (2014). A Guide to Using Case-Based Learning in Biochemistry Education. Biochemistry and Molecular Biology Education, 42(6), 457-473.

Lei, J. H., Guo, Y. J., Chen, Z., Qiu, Y. Y., Gong, G. Z., \& He, Y. (2016). Problem/Case-based Learning with Competition Introduced in Severe Infection Education: An Exploratory Study. Springerplus, 5 .

Mahgoub, S., \& Nadeem, F. (2012). Interactive Case Based Learning in Teaching Decision Support Systems and Business Intelligence. Proceedings of the 13th International Conference on Interaccion Persona-Ordenador (Interaccion'12).

Melo, P. H., Hannois, F. G., Rodrigues, F. A., \& Natal, F. J. (2011). Active Learning on the Ward: Outcomes from a Comparative Trial with Traditional Methods. Medical education, 45(3), 273.

Nkhoma, M. Z., Lam, T. K., Richardson, J., Kam, K., \& Lau, K. H. (2016). Developing Case-based Learning Activities based on the Revised Bloom's Taxonomy. Paper presented at the Proceedings of Informing Science \& IT Education Conference.

Nkhoma, M. Z., Lam, T. K., Sriratanaviriyakul, N., Richardson, J., Kam, B., \& Lau, K. H. (2017). Unpacking the Revised Bloom's Taxonomy: Developing Case-based Learning Activities. Education and Training, 59(3), 250-264.

Olson, S., \& Riordan, D. G. (2012). Engage to Excel: Producing on Million Additional College Graduates with Degrees in Science, Technology, Engineering, and Mathematics. Report to the President. Executive Office of the President, 130.

Raurell-Torreda, M., Olivet-Pujol, J., Romero-Collado, A., Malagon-Aguilera, M. C., Patino-Maso, J., \& Baltasar-Bague, A. (2015). Case-based Learning and Simulation: Useful Tools to Enhance Nurses' Education? Nonrandomized Controlled Trial. Journal of Nursing Scholarship, 47(1), 3442.

Razzouk, R., \& Johnson, T. E. (2013). Case Studies' Effect on Undergraduates' Achievement, Attitudes, and Team Shared Mental Models in Educational Psychology. Etr\&D-Educational Technology Research and Development, 61(5), 751-766.

Rodriguez-Sanchez, M. C., Torrado-Carvajal, A., Vaquero, J., Borromeo, S., \& Hernandez-Tamames, J. A. (2016). An Embedded Systems Course for Engineering Students Using Open-Source Platforms in Wireless Scenarios. Ieee Transactions on Education, 59(4), 248-254.

Shetty, J. K., Begum, G. S., Goud, M. B. K., \& Zaki, B. (2016). Comparison Of Didactic Lectures And Case-Based Learning In an Undergraduate Biochemistry Course at Rak Medical And Health Sciences University, Uae. Journal of Evolution of Medical and Dental Sciences-Jemds, 5(50), 3312-3316.

Tan, J., Guo, X. P., Zheng, W. S., \& Zhong, M. (2014). Case-based Teaching Using the Laboratory Animal System for Learning C/C Plus Plus Programming. Computers \& Education, 77, 39-49. 
Thiel, C. E., Connelly, S., Harkrider, L., Devenport, L. D., Bagdasarov, Z., Johnson, J. F., \& Mumford, M. D. (2013). Case-Based Knowledge and Ethics Education: Improving Learning and Transfer Through Emotionally Rich Cases. Science and Engineering Ethics, 19(1), 265-286.

Yadav, A., Bozic, C., Gretter, S., \& Nauman, E. (2015). Benefits and Challenges of Implementing Casebased Instruction: A Student Perspective. International Journal of Engineering Education, 31(6), 1554-1563.

Yadav, A., Vinh, M., Shaver, G. M., Meckl, P., \& Firebaugh, S. (2014). Case-based Instruction: Improving Students' Conceptual Understanding Through Cases in a Mechanical Engineering Course. Journal of Research in Science Teaching, 51(5), 659-677.

Yoo, M. S., \& Park, H. R. (2015). Effects of Case-based Learning on Communication Skills, ProblemSolving Ability, and Learning Motivation in Nursing Students. Nursing \& Health Sciences, 17(2), 166-172.

154 Journal of Higher Education Theory and Practice Vol. 19(6) 2019 